\title{
Innovation and entrepreneurship in Romania's cultural and creative industries
}

\author{
Laura Gabriela ISTUDOR \\ The Bucharest University of Economic Studies, Bucharest, Romania \\ laura.istudor@gmail.com
}

\begin{abstract}
The evolution of entrepreneurship in the cultural and creative sectors leads to social innovation by creating new jobs intended for the creative class and by building a long-run smart, sustainable and inclusive local development. Innovation and sustainability are concepts that can be applied to many industries, and they can involve numerous improvements related but not limited to processes, products, services, logistics. This paper supports the idea that the creative and cultural sectors can develop through innovative entrepreneurship, by introducing new methods of production, optimizing existing processes, improving the delivery methods or by developing new products or services, while also relying on the help of the government and smart organizations such as clusters. Since innovation involves improving the way of doing business, this paper will focus on identifying the available innovative methods that can be applied to the businesses activating in the cultural and creative sectors of the economy in Romania, together with the main challenges and opportunities that might arise by applying them. The perspectives of intellectual capital, creative economy and knowledge-based society in relation to the impact of innovation and entrepreneurship towards the development of the cultural and creative sectors in Romania will also be considered. The paper will also tackle a series of best practice examples of innovative businesses in the creative sectors, as well as a comparative analysis of the successfully implemented innovative ideas in this field of activity and their impact on the customer satisfaction and on the development of the local economy.
\end{abstract}

Keywords: innovation, creative industries, innovative entrepreneurship, entrepreneurship, clusters.

\section{Introduction}

Innovation and sustainability are trending concepts nowadays when tackling topics regarding the development of the modern societies. For societies which reached the innovation-driven stage, the only way to develop is through innovation, which in turn is based on human creativity. The concept of creative economy, first mentioned by John Howkins (2001) had an outstanding evolution over the years and is currently applied to several activities.

Certain cultural and creative sectors of the economy have been distinguished (Howkins, 2001), including but not limited to design, architecture, research, publishing, video games, theatre. However, innovation can appear in all the activities of an economy, regardless if it is an efficiency-driven economy or an innovation-driven economy, contributing to the progress of industries across the globe. (Hartley, 2015)

Since innovation is not limited to the IT industry or to the artistic industries, it is of great importance to acknowledge the importance of innovating in every sector of the economy, as the improvement of processes and the development of new techniques can lead to an increase in productivity (Suciu, 2008).

This paper documents the extent to which the entrepreneurship in the creative industries contribute to innovation and sustainability in Romania. Intellectual capital is the 
basis of innovation, leading to the development of societies through the creativity of people, through technological, artistic and scientific advancement.

The topic of clusters and government support for entrepreneurs activating in the cultural and creative sectors of the economy will also be discussed, within the context of sustainable development and creative economy.

\section{Literature review}

The creative industries have been defined for the first time about a decade and a half ago, (Caves 2000; Howkins 2001) and their definition is still evolving as the phenomenon is very dynamic and the products generated by these industries are not traditional products, therefore not easily quantifiable.

Richard Florida, another pioneer of creative economy, went on laying out the significance of the human resources which are the basis of creativity, treating it as an economic resource of crucial importance and highlighting the role of the 3 T's (technology, talent, tolerance) in the development of a society (Florida, 2002). Richard Florida and The Martin Prosperity Institute are presently contributing to the execution of a fourth $\mathrm{T}$, referring to territory, a component related to the economic development of local and regional creative groups.

The creative sectors are composed of industries that rely on human creativity in order to generate welfare (UNCTAD, 2010), where human creativity is the essential factor that creates new ideas to keep the industry developing.

Several authors described the creative industries with the help of the fundamental domains they include, among which Hesmondhalgh (2002) and Howkins (2001) mention advertising, video games, editing, radio, film.

The concepts of creative economy and knowledge-based society have been noted and supported by the European Union through projects such as „Creative Europe", and „Europe 2020", which followed "Lisbon Strategy", with the main goal to create a smart, sustainable development, that encourages job creation and inclusion. In such manner, the methodology states among the most imperative segments innovation and research and development (European Commission, 2013).

Creative economy is not easily measured, but it can be realized by employing economic indicators such as work, exchange, buyer consumption, yet additionally by including indicators like intellectual property rights.

Measuring a creative economy can be a very challenging task with regards to the measurement of ideas, designs, theories, due to the intangible aspects. Innovation decides an alternate way of working, involving non-financial related exchanges and numerous freelancers and part-time workers.

\section{Methodology}

Social innovation has a determinant factor in entrepreneurship, as a driving force for economic development. In the cultural and creative sectors, local economic development can be enhanced through the creation of new jobs for the members of the creative class. Thus, new creative products will appear and take various shapes, from designs, materials, to theories, brought on the market to satisfy consumer needs and leading to the development of knowledge in their sector. (Suciu, 2004) 
The entrepreneurs are the ones that introduce new technologies, stimulate the discovery of new resources and promote new products, ensuring jobs for the better part of the population of the world.

According to the benchmarking tool entitled „European Innovation Scoreboard"(EIS), a yearly publication belonging to the European Commission published in 2016 (European Commission, 2016), which entails updated statistics up to 2016, Romania is placed at the end of the ranking together with Bulgaria, out of the countries of the European Union, in regard to the innovation in economy (figure 1).

The methodology includes the estimation of the innovation performance with the help of the Summary Innovation Index, a composite indicator based on three main pillars: the enablers, (for example, HR, doctorate graduates), firm activities (entrepreneurship, firm ventures, linkages) and outputs (cutting edge product experts).

All the member states of the EU are assessed and positioned in view of a total of 25 criteria, such as the number of PhD students, the number of issued patents, investments in research and development.

The Global Entrepreneurship Monitor (GEM) is another benchmarking tool that gathers a considerable volume of information from several countries, assessing the concrete connections between the entrepreneurial activity and the economic growth of a country.

The data collected by GEM is used with the final purpose of realizing a set of indicators that measure the connection between the entrepreneurial activity and the goals and attitudes of the individuals. It also gathers information on elements that contribute to the development of entrepreneurship in a certain country, such as governmental support, fiscalism, financial resources for small and medium enterprises (SMEs), entrepreneurial education, R\&D activities, the business infrastructure, together with social and cultural norms and the impact of the activity of the SMEs on the economy.

The Global Entrepreneurship Monitor has been issued 18 times until now, with the last issue of the report being released with data for 2016/2017. Romania was not included in the countries analyzed in the last issue, however it was included in the 2015/2016 issue of the report.

The report comprising data for 2015/2016 is an assessment of motivations, ambitions and characteristics of entrepreneurs and the attitude of each society included in the study towards entrepreneurship.

The report includes results for 62 economies, and the major findings of the report highlight the fact that $68 \%$ of adults consider that people employed in entrepreneurial activities have a high status in the society, while $42 \%$ of them consider they have good opportunities for starting a business, of which $1 / 3$ would not pursue this action due to the fear of failure.

\section{Results and discussions}

According to the European Innovation Scoreboard (EIS), Romania obtained low scores in entrepreneurship and intellectual property rights (European Commission, 2016). The country enlisted the lowest results over a period of eight years, registering a negative growth rate between 2008-2015, as opposed to Latvia's and Malta's evolution, countries showing the most notable development in the course of a similar timeframe. 
Romania and Bulgaria are considered to be modest innovators, being placed below the average value of the countries in the European Union in terms of innovation in the economy. The EIS had its fifteenth issue in 2016, providing a situation of the development of the Member States of the EU since 2001 onwards, helping them to coordinate their endeavors in the direction of improving the less developed areas.

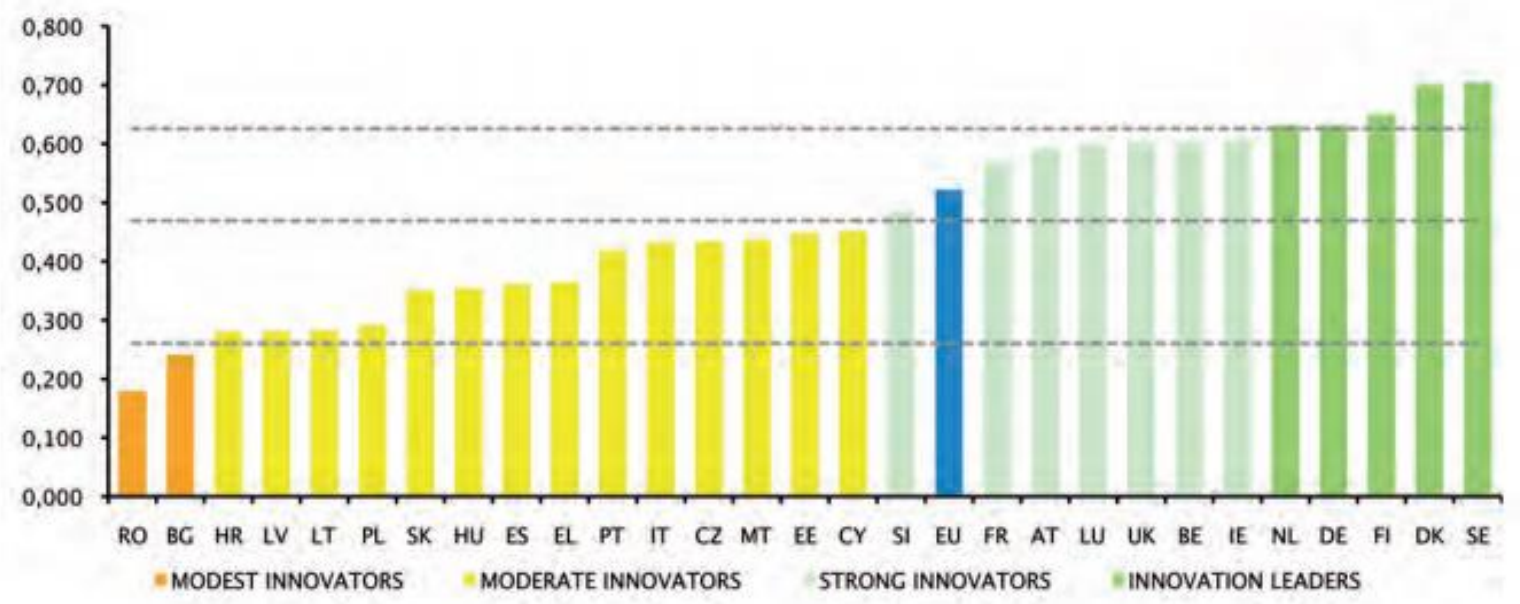

Figure 1. The innovation level of the EU Member States

Source: European Innovation Scoreboard, European Commission, 2016.

According to the Global Entrepreneurship Monitor (GEM), out of the 62 economies studied, over a half of the adults of working-age consider that they can develop a business, while only $21 \%$ of the people surveyed have the intention of opening a business in the following three years.

The main motivation for entrepreneurs around the world to start a business comes from opportunity. Therefore, the report found that in the efficiency-driven and in the factor-driven economies 69\% of the existing entrepreneurs started their businesses pursuing an opportunity, not a need, while in the innovation-driven economies included in the study, the percentage of entrepreneurs that were opportunity-motivated reaches $78 \%$.

Considering the age distribution of the entrepreneurs in the countries analyzed, the highest percentage of them have ages between 25-34 and 35-44 years old, which are people found at the beginning of their careers or in the mid-career stages.

When it comes to the industries in which they activate, more than half of the business owners from factor-driven and efficiency-driven economies are doing business in the retail or wholesale sectors, while almost half of the business-owners in the innovationdriven economies launched their businesses in IT, finance, health, professional, education and several other services sectors.

As stated before, the creation of new businesses contributes to the increase in innovation and therefore leads to the economic development of societies. According to the Global Entrepreneurship Monitor, the level of innovation in factor-driven economies was situated at 21\%, while in efficiency-driven economies it registered $24 \%$ and in the innovation-driven ones it reached 31\%, showing an ascendant path in accordance with the development level. 
The report includes data gathered from 60 economies around the world, among which 10 countries representing the factor-driven economies from Africa and Asia \& Oceania, 29 countries representing the efficiency-driven economies from Africa, Asia \& Oceania, Latin America \& Caribbean, Europe (where Romania was also included) and 23 countries representing the innovation-driven economies from Asia \& Oceania, Europe and North America.

PICBE $\mid 502$

The classification of the economies included in the report by geographic region was adapted based on data provided by the United Nations, while the classification regarding the economic advancement was realized based on World Economic Forum data, in accordance with its definitions of the different stages of development of societies.

Therefore, the factor-driven economies are relying on natural resources, unskilled labor and agriculture and extraction businesses, the efficiency-driven economies are more industrialized and rely on economies of scale, also featuring competitiveness and dominant organizations on the market, while the countries that reached the innovation-driven phase have extensive service sectors and comprise knowledge-intensive businesses.

Every country in the report was granted an in-depth analysis of several indicators in order to rank it in comparison to the other participants to the study. At the moment, Romania had a small and medium business contribution to GDP of $50 \%$ and was considered to be in the efficiency-driven economic development phase.

In the case of Romania, in terms of self-perceptions about entrepreneurship, 33\% of the Romanian working-age citizens perceive business opportunities around them, leading Romania to the 45 th spot of the ranking, while $46.3 \%$ of them think they are able to start a business, leading our country to the 35 th spot of the ranking.

When subtracting the ones who do not pursue an entrepreneurial drive due to the fear of failure, we are left with $40.5 \%$ people. The percentage of citizens who are interested in opening their own business in the course of the following three years is $29 \%$, leading Romania to the 16th spot of the Global Entrepreneurship Monitor in the 2015/2016 issue.

In terms of activity in entrepreneurship in our country, the total entrepreneurial activity (TEA) for early stage businesses has shown an increase from 2013 to 2015, up from $10.1 \%$ in 2013 , to $11.4 \%$ in 2014 and to $10.8 \%$ in 2015.

For the established businesses, the ownership rate was situated at $7.5 \%$, while the entrepreneurial employee activity (EEA) was estimated at 4.6\%, positioning Romania on the 17 th position in the ranking. The figures can be seen below:

\begin{tabular}{lcc}
\hline Activity & Value $\%$ & Rank/60 \\
\hline $\begin{array}{l}\text { Total Early-stage Entrepreneurial Activity } \\
\text { TEA 2015 }\end{array}$ & 10.8 & 30T \\
\hline TEA 2014 & 11.4 & $\mathrm{n} / \mathrm{a}$ \\
\hline TEA 2013 & 10.1 & $\mathrm{n} / \mathrm{a}$ \\
\hline Established business ownership rate & 7.5 & 25 \\
\hline Entrepreneurial Employee Activity - EEA & 4.6 & 17 \\
\hline
\end{tabular}

Figure 2. Entrepreneurial activity in Romania

Source: Global Entrepreneurship Monitor 2015/2016 Global Report.

DOI: 10.2478/picbe-2018-0045, pp. 498-507, ISSN 2558-9652| Proceedings of the $12^{\text {th }}$ International Conference on Business Excellence 2018 
In terms of motivation, the drive for starting a business and improving it due to the opportunities arising around them or out of necessity, we will find the value of 1.2 in the survey, leading Romania to the 49th position.

Considering gender equity, the ratio between female/male total entrepreneurial activity, Romania had a value of 0.5 , while recording 1.1 in female/male opportunity ratio.

Entrepreneurship has an impact on the local economy and contributes to job creation. In GEM 2015/2016, the entrepreneurship impact in Romania in terms of job expectations recorded $39.8 \%$, helping the country to classify as the 4th country in ranking in the report.

The innovation level increased in Romania by 3.2\% compared to the previous issue of the report, while in the business services sector, entrepreneurial ventures had an impact of $17.6 \%$.

People view entrepreneurs in different ways according to their perceptions. In Romania, $75.1 \%$ of the people interviewed perceive entrepreneurs as having a high status in the society, situating Romania on the 18th position in the ranking in terms of societal value about business owners. Also, $72.4 \%$ of the participants in the survey consider that entrepreneurship is a good career choice.

The GEM ranked the entrepreneurial eco-system of every country included in the study considering several dimensions and ranking the countries based on the value between 1 and 9 registered by every country.

In the case of Romania, the physical infrastructure vas evaluated at 4.75 , ranking $27 / 62$ economies, the cultural and social norms were estimated at 4.75, ranking 31/62 economies, while entrepreneurial finance registered 3.95, ranking 38/62.

In terms of government policies supporting the development of new businesses, Romania was evaluated at 3.65, ranking 48.62, 4 for government entrepreneurship programs, 3.7 for entrepreneurship in schools and 4.2 in entrepreneurship education in the post school stage.

The commercial and legal infrastructure received 5.06 points, ranking 25/62 economies considered, while the internal market dynamics received 4.71 points, ranking $36 / 62$ and the internal market burdens or entry regulation dimension was situated on the 12 th position with 4.68 points. The results can be seen in the below figure: 


\section{Expert Ratings of the Entrepreneurial Eco-system (rank out of 62 recorded in brackets)}

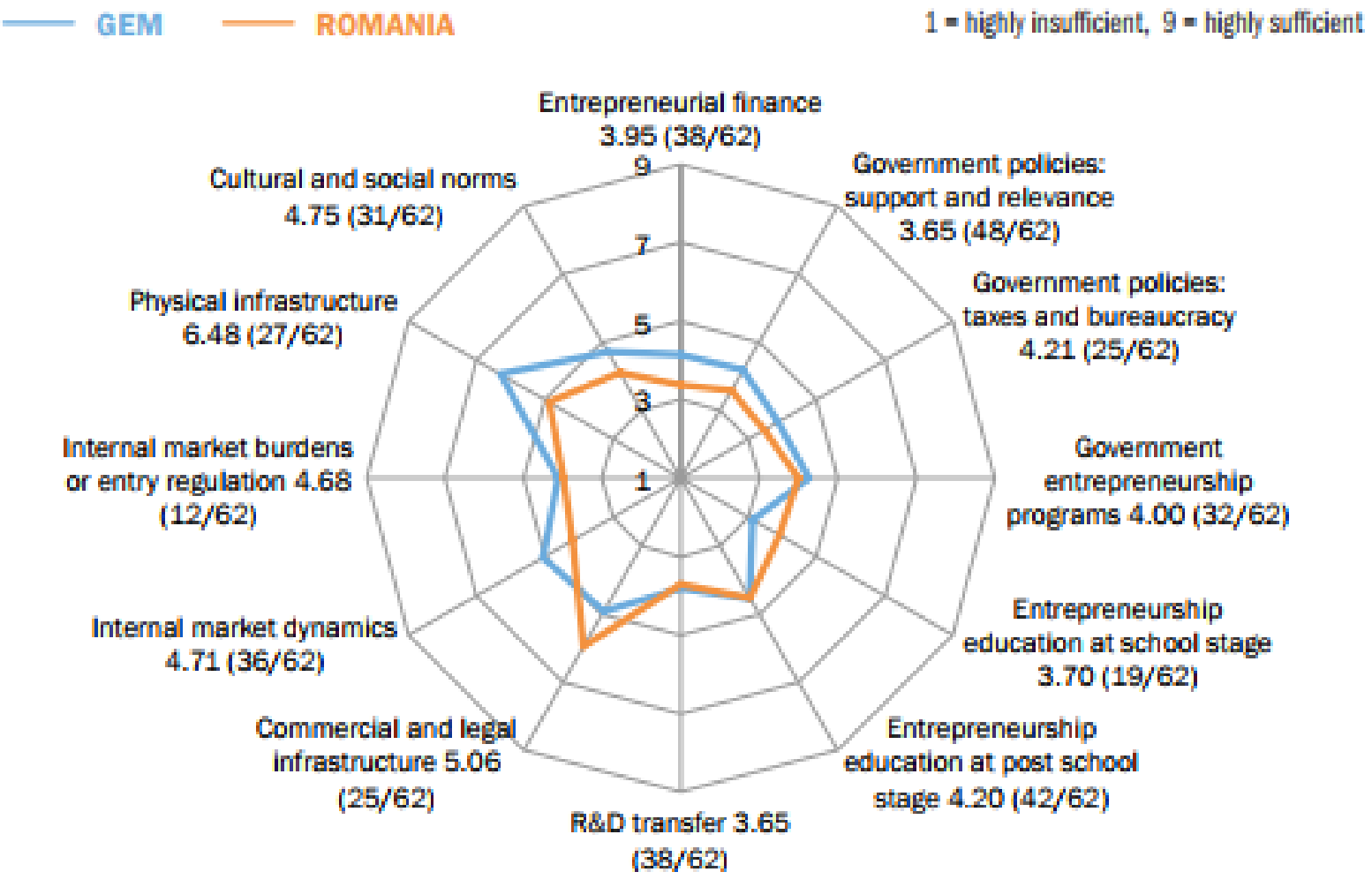

Figure 3. Entrepreneurial activity in Romania

Source: Global Entrepreneurship Monitor 2015/2016 Global Report.

The first Romanian study offering a view of entrepreneurship in the creative sectors of Romania, the Barometer of the Creative Minds, was launched in October 2017 by Unicredit Bank in collaboration with Exact Research and Consultancy agency. The study was realized by using both qualitative and quantitative research methods.

The results of the study comprise the answers of over 70 entrepreneurs occupying lead positions in small and medium enterprises of the creative industries as stated by the CAEN codes of Romania.

The main results of the study show the way the entrepreneurs activating in the innovative industries in Romania view the current situation of their businesses, the barriers encountered, the financing issues as well as the human resources dimension.

In terms of the current economic situation of Romania, $90 \%$ of the entrepreneurs interviewed consider that the economic context is unfavorable and that the constant changes in legislation can have a negative impact on the development of their business. Out of the total, $45 \%$ of them take into consideration expanding their businesses in the near future.

The most common challenges encountered by the entrepreneurs activating in the creative industries in Romania are related to the high taxes, according to $70 \%$ of the interviewees, while $57 \%$ of them consider that the economic context is a barrier and $46 \%$ have encountered issues with cash flow. 
The main difficulties when it comes to financing their businesses are related to the bureaucracy in the public financing programs, $47 \%$ of the participants in the survey confirm, while $30 \%$ of them encountered a reticence on the banks side when applying for a loan.

Over $50 \%$ of the entrepreneurs included in the study consider that European funding is necessary for their businesses, and the same percentage require online banking services such as mobile banking and online payments to better adapt to current conditions.

Over $65 \%$ of the entrepreneurs interviewed intend to increase the number of employees in 2018, for full time jobs, targeting young candidates, aged between 18-34 years old. For the employers, the most important traits in a candidate are their enthusiasm and involvement, 55\% say. Their adaptability to the organizational culture of the company ranks next in terms of importance, with $35 \%$ respondents, while the personality of the candidate ranks third, with $30 \%$ responses.

Only $17 \%$ of the entrepreneurs interviewed value the previous experience in the field, while 7\% grant a great importance to the field of study of the candidates.

According to the Romanian Ministry of Economy, the creative sectors contributed to the PIB with $7 \%$ in 2016, while the goal set for 2020 is to reach a $10 \%$ contribution. Programming and IT occupy a large percentage of the creative industries in Romania, followed by the artistic and cultural sectors.

According to Michael Porter, "Clusters are geographic concentrations of interconnected institutions and companies from a certain domain." Usually, they bring together companies from interconnected industries, that can in time develop towards their distribution channels or in the direction of production of complementary products. (Porter, 1998)

Starting with 2008, the Ministry of Economy, Commerce and Business Environment of Romania started to carry out actions in order to identify the existing clusters in the country through a "cluster mapping” exercise, a project called „Inov Cluster” carried out between 2008-2010 with the purpose of disseminating the information regarding innovation clusters and the best practice examples identified at an international level and several other initiatives.

As of the 1st of July 2011, the Romanian Cluster Association was established and had 15 clusters as founding members, representing domains such as IT, automotive, agro-food, electrotechnical industry and wood industry. In the meantime, several other clusters have joined the association, whose main purpose is to lead Romania towards an economic development through creation, development and collaboration among the clusters at the regional, national and international level.

Cluj IT is an example of a cluster established in 2012, member of the Romanian Cluster Association, which is composed of organizations activating in the IT industry such as services and software providers, universities and public entities. The purpose of the cluster is to increase competitivity in the IT sector and promoting Romania as a top software provider in Eastern Europe.

Cluj IT continuously promotes process innovation, the creation of new products and services that increase its competitivity at the international level, the advertising of the IT industry from Romania, the establishment of sustainable private and public partnerships that will bring mutual benefits to the members of the cluster and to the society in general. 


\section{Conclusions}

Creative economy is a globally known concept and new type of economy developed during the past decade and nowadays it is viewed as an important factor for economic development.

Considering the current level of globalization and technological advancement, the economies of the world can develop through innovation, for which the most important driver is represented by the human resources, through creativity that leads to innovation.

Entrepreneurship is a leading force towards economic development, especially in the cultural and creative sectors of the economy. At the global level, the topic of entrepreneurship is granted a great importance, in the context of the European Union strategies that promote social inclusion, job creation, innovation and research of development.

In Romania, the entrepreneurial area started to be considered a growth generator for the economy, but the entrepreneurs activating in the creative industries encounter several challenges in the establishment and development of their businesses.

Romanian entrepreneurs identify a need for financing new businesses from european funds, as most of the times they cannot afford to support a business from their own funds. The government developed public financing programs, however the procedures are lenghty and complicated and the funds are not easily accesible.

The current paper starts with a literature review on creative economy, continuing with a gathering of statistics related to the input of entrepreneurship to the economic development of nations.

The Romanian Ministry of Economy declared that the creative sectors contributed to the GDP with $7 \%$ in 2016 , while the goal set for 2020 is to reach a $10 \%$ contribution. The establishment of regional and national clusters to increase competitiveness in several creative sectors of the economy as well as the public and private funding programs available for entrepreneurs led to an increase in new business creation.

Romania is one of the countries position at the end of the ranking in terms of innovation in the economy, when compared to the rest of the EU member states as shown by the EIS - European Innovation Scoreboard study released in 2016. According to EIS, Romania was assessed and positioned in view of 25 criteria in total, among which the number of $\mathrm{PhD}$ graduates, patents issued, workers in high-tech industries. Romania ranks low in intellectual property rights and entrepreneurship, showing the lowest results in terms of growth rate between 2008-2015 (European Commission, 2016).

In terms of self-perceptions about entrepreneurship, according to the Global Entrepreneurial Monitor, 33\% of the Romanian working-age citizens perceive business opportunities around them, leading Romania to the 45th spot of the ranking, out of 62 economies, while $46.3 \%$ of them think they are able to start a business, leading our country to the 35th spot of the ranking.

When subtracting the ones who do not pursue an entrepreneurial drive due to the fear of failure, the percentage left is $40.5 \%$. The percentage of citizens who would decide to launch a new business within the course of the following three years is of $29 \%$, leading Romania to the 16th spot of the Global Entrepreneurship Monitor in the 2015/2016 issue.

A future research line should follow the thorough analysis of the Romanian clusters involving creative activities, as well as the creation of a comparative analysis of best practice examples. In order for Romania to increase its current innovation level of the 
economy, there is a necessity involving the acknowledgement of the Government towards the creative and cultural sectors, and to develop programs that support them.

In conclusion, according to several international benchmarking tools, Romania is a modest innovator, but the creative industries contribution to the GDP has increased over the years and the existence of several regional and national clusters place Romania in a competitive position in Eastern-Europe, especially in terms of IT products and services. Government support for the cultural and creative industries can lead to more individuals activating in the creative sectors of the economy which in turn leads to the development of new businesses, regional communities and innovative clusters that can generate mutual benefits.

\section{References}

Caves, R. E. (2000). Creative Industries. Contracts between Art and Commerce. Cambridge, MA: Harvard University Press.

Clustero (2015). Romanian Cluster Association. Retrieved from http://clustero.eu/romanian-cluster-association/

Clustero (2015). Cluj IT. Retrieved from http://clustero.eu/cluj-it-en/

Exact Research and Consultancy, \& Unicredit Bank (2017). The Barometer of Creative Minds. Retrieved from http://www.institute.ro/design/barometrul-mintilor-creative2714.html

Kelley, D., \& Singer S., \&Herrington, M. (2016). GEM 2015 / 2016 Global Report. Retrieved from http://www.gemconsortium.org/report/49480

European Commission (2016). European Innovation Scoreboard. Retrieved from European Commission: http://ec.europa.eu/growth/industry/innovation/facts-

figures/scoreboards_en

European Commission (2013). Europe 2020. Retrieved from European Commission: http://ec.europa.eu/growth/tools-

databases/newsroom/cf/itemdetail.cfm?item_type=251\&lang=en\&item_id=6854

European Commission (2016). European Innovation Scoreboard. Retrieved from

http://www.knowledgetransferireland.com/About_KTI/Reports-

Publications/European-Innovation-Scoreboard-2016.pdf

Florida, R. (2002). The Rise of the Creative Class. Basic Books.

Hartley, J. (2015). Creative Economy and Culture: Challenges, Changes and Futures for the Creative Industries. SAGE Publications Ltd.

Hesmondhalgh, D. (2002). The Cultural Industries. SAGE Publications Ltd.

Howkins, J. (2001). The Creative Economy: How People Make Money From Ideas. United Kingdom: Penguin UK.

NESTA (2016). Cultural Policy in the time of the creative industries. Retrieved from http://www.nesta.org.uk/sites/default/files/cultural_policy_in_the_time_of_the_crea tive_industries_pdf

Suciu, M. C. (2004). Economia si societatea bazata pe cunoastere/Economy and knowledgebased society. Vol II, Ch. 19. Bucharest, RO: Editura ASE Bucuresti.

Suciu, M. C. (2008). The Creative Economy. Vol. 15, Issue 1. Bucharest, R0: Lex et Scientia. UNCTAD (2010). Creative Economy: A Feasible Development Option. UNDP. 